\title{
ANÁlise dAS RELAÇÕES ECONÔMICAS, COMERCIAIS E DE COOPERAÇÃO DA AMÉRICA LATINA E DO CARIBE COM OS EsTADOS UNIDOS DA AMÉRICA*
}

CRAIG VANGRASSTEK ${ }^{\dagger}$

\section{UM DOSSIÊ SOBRE ANÁlise ECONÔMICA Do DiREITO}

\footnotetext{
* Traduzido do inglês para o português, com a autorização do autor, por Aline Brayner e revisado por Luciana Silveira, do texto Analysis of Economic, Trade and Cooperation Relations of Latin America and the Caribbean with the United States of America, sendo uma adaptação condensada de um relatório com o mesmo título emitido pelo Latin American Economic System (SELA). Disponível em: $<$ http://www.sela.org/media/2465350/craig-vangrasstek-def-07-09-17-mm.pdf $>$. As seções apresentadas aqui tratam principalmente de comércio e investimento. $\mathrm{O}$ relatório completo oferece mais detalhes sobre essas questões e também trata de outras áreas das relações econômicas internacionais (por exemplo, imigração e assistência externa). Aline Brayner é Graduanda em Direito pela Universidade Federal do Rio de Janeiro (UFRJ) e Pesquisadora do Laboratório de Estudos Teóricos e Analíticos sobre Comportamento das Instituições (LETACI). E-mail: alinebrayner@outlook.com. Luciana Silveira é Mestranda pelo Programa de Pós-Graduação em Direito da Universidade Federal do Rio de Janeiro (PPGD/UFRJ) e Pesquisadora do Laboratório de Estudos Teóricos e Analíticos sobre o Comportamento das Instituições (LETACI). Email: lucianasilveirardente@gmail.com.

${ }^{\dagger}$ Professor de Economia Política na Harvard Kennedy School, consultor da Organização Mundial do Comércio (OMC), da Organização de Cooperação e Desenvolvimento Econômico (OCDE), da Conferência das Nações Unidas sobre Comércio e Desenvolvimento, do Banco Mundial e de outras organizações internacionais, bem como agências governamentais e empresas privadas.
} 
SUMÁRIO:

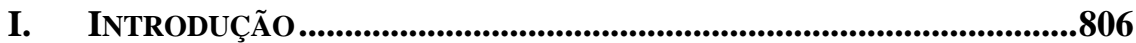

II. COMÉRCIO E INVESTIMENTO DOS EUA COM A AMÉRICA LATINA E

O CARIBE ...........................................................................................806

1. Tendências no comércio......................................................................806

2. Tendências no investimento..............................................................809

III. Política ECONÔMICa eStrangeira NORTe-AMERICana

SOB O NOVO GOVERNO DOS EUA .......................................................812

1. Backlash anti-globalização .............................................................812

2. $\mathrm{O}$ ressurgimento do protecionismo ...............................................815

3. O retorno das ameaças retaliatórias............................................817

4. 0 impacto da rivalidade sino-americana em terceiros..............819

IV. CONCLUSÕES........................................................................................823

1. O que o desengajamento econômico dos EUA significa para a região ..................................................................824

2. Os riscos para o sistema de negociação multilateral ..................825

\section{TABLE OF CONTENTS:}

I. INTRODUCTION ...................................................................................806

II. U.S. TRADE AND INVESTIMENT WITH LATIN AMERICA AND THE

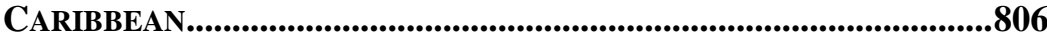

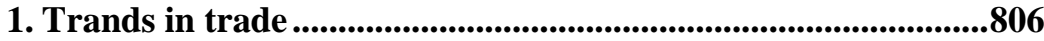

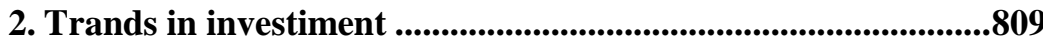

III. U.S. FOREIGN ECONOMIC POLICY

UNDER THE NEW U.S. GOVERNMENT............................................8812

1. The anti-globalization backlash ...................................................812

2. The resurgence of protectionism..................................................815

3. The return of retaliatory threats.................................................817

4. The impact of the sino-americans rivalry on third parties......819

IV. CONCLUSIONS ............................................................................................823

1. What the U.S. economic disengagement means for the region.........................................................................................824

2. The risks for the multilateral trading system ..............................8825 


\section{INTRODUÇÃO}

Se as principais tendências, nas relações econômicas dos Estados Unidos da América (EUA) com a região, tivessem de ser reduzidas a uma única sentença, seria esta: depois de algumas décadas buscando iniciativas voltadas para a promoção de relações econômicas interamericanas mais próximas, que se reuniram com graus amplamente variáveis de sucesso, os EUA agora estão se afastando de seus parceiros do Sul. Isso pode ser visto não apenas nos dados econômicos, que mostram que o comércio estagnou e o capital de investimento dos EUA está sendo redirecionado para outras regiões, mas também na reversão de iniciativas comerciais. Durante 1991 e 2006, os EUA negociaram Acordos de Livre Comércio - FTAs (Free Trade Agreements) com onze países da região e também tentaram implementar uma Área de Livre Comércio das Américas. Não houve novos acordos bilaterais ou subregionais de comércio desde então e o novo governo dos EUA ameaça avançar na direção oposta. Ele já retirou os EUA de um dos principais acordos comerciais pendente em que três países latino-americanos são membros, exigiu a renegociação de outro acordo e ordenou uma revisão do restante. As ações em outras áreas, como demandas de um muro na fronteira entre os EUA e México e propostas para cortar a assistência externa, reforçam essa tendência para o desengate econômico.

As relações econômicas entre os EUA e seus parceiros latinoamericanos e caribenhos, portanto, estão se afastando, e há todos os motivos para esperar que eles se tornem mais distantes e controversos nos próximos anos. Esta análise elabora esse ponto geral, com base nas tendências econômicas estabelecidas, bem como nos objetivos declarados do novo governo dos EUA.

\section{COMÉRCIO E INVESTIMENTO DOS EUA COM A AMÉRICA LATINA E O CARIBE}

\section{Tendências no comércio}

Mesmo depois de explicar a desaceleração da crise de 2008-2009, o comércio total de mercadorias (ou seja, as importações somadas às exportações) entre os EUA e os países da América Latina e do Caribe passou de US\$ 228 bilhões, em 1996, para US\$ 782 bilhões em 2012. Essa foi uma taxa composta de crescimento de $8 \%$ ao ano. O total caiu para US\$ 696 bilhões, em 2016, uma queda de 11\% em relação a 2012. O 
declínio, no comércio, não é exclusivo das importações da região para os EUA; as importações do resto do mundo caíram 6\% entre 2012 e 2016. Essa tendência também não é restrita aos EUA. Numerosos comentadores notaram uma queda recente no comércio global, atribuindo-o de forma diversificada a um crescimento mais lento, preços mais baixos e mais protecionismo.

A Tabela 1 oferece uma visão sobre as importações de mercadorias nos EUA em 2016. As taxas sobre as importações para os EUA que vêm dos países da América Latina e do Caribe são um fator pequeno e decrescente nessas relações. Considerando que cerca de um quarto de todas as exportações da América Latina e do Caribe para os EUA ainda era compatível, em 1996, isso caiu para menos de $10 \%$ em 2016. As taxa médias dos EUA, em relação a todos os parceiros, foram substancialmente reduzidas nas negociações comerciais do Rodada do Uruguai, cujos resultados foram introduzidos gradualmente durante 1995-2005 e os tributos caíram ainda mais rapidamente para as importações dos países da América Latina e do Caribe. Esse ponto é especialmente importante para os parceiros de FTA dos EUA, para quem as tarifas médias estão agora abaixo de apenas $0,2 \%$, mas a maioria dos outros países da região também enfrenta barreiras tarifárias baixas. Existem apenas sete países que enfrentaram tarifas médias de $1 \%$ ou mais em 2016. Eles incluíram dois parceiros de FTA para os quais algumas exportações de vestuário ainda são realizadas fora do âmbito do acordo (Guatemala e Nicarágua); quatro países que ainda eram beneficiários das preferências em 2016 (Bahamas, Brasil, Haiti e Uruguai); e um país que havia sido removido das preferências (Argentina). Considerada como um todo, a alíquota média de todas as importações da região para os EUA foi de apenas 0,3\%, em 2016 (abaixo de 3,1\% em 1990); a alíquota média dos produtos ainda sujeitos a incidência tributária era de 2,8\% (abaixo de 4,4\% em 1990). 
Tabela 1 - Tratamento tributário das importações para os EUA

da América Latina e do Caribe, 2016

(milhares de dólares e percentuais atuais)

\begin{tabular}{|c|c|c|c|c|c|c|}
\hline & & \multicolumn{2}{|c|}{ Importações tributáveis } & \multirow[b]{2}{*}{ Arrecadação } & \multicolumn{2}{|c|}{ Taxa de arrecadação sobre } \\
\hline \multicolumn{2}{|c|}{ Total de importações } & Valor & Proporção & & Importações & Tributável \\
\hline Parceiros FTA & $345,313,987$ & $18,190,045$ & $5.0 \%$ & 558,177 & $0.2 \%$ & $3.1 \%$ \\
\hline Chile & $8,848,962$ & 160,099 & $1.8 \%$ & 4,456 & $0.1 \%$ & $2.8 \%$ \\
\hline Colombia & $13,805,930$ & $3,039,076$ & $22.0 \%$ & 9,389 & $0.1 \%$ & $0.3 \%$ \\
\hline Costa Rica & $4,332,321$ & 111,941 & $2.6 \%$ & 3,835 & $0.1 \%$ & $3.4 \%$ \\
\hline Rep. Dominicana & $4,649,066$ & 207,171 & $4.5 \%$ & 11,379 & $0.2 \%$ & $5.5 \%$ \\
\hline El Salvador & $2,480,231$ & 108,683 & $4.4 \%$ & 15,842 & $0.6 \%$ & $14.6 \%$ \\
\hline Guatemala & $3,925,631$ & 374,179 & $9.5 \%$ & 57,043 & $1.5 \%$ & $15.2 \%$ \\
\hline Honduras & $4,544,676$ & 147,557 & $3.2 \%$ & 20,717 & $0.5 \%$ & $14.0 \%$ \\
\hline México & $292,836,207$ & $13,125,007$ & $4.5 \%$ & 344,524 & $0.1 \%$ & $2.6 \%$ \\
\hline Nicarágua & $3,273,096$ & 491,090 & $15.0 \%$ & 84,223 & $2.6 \%$ & $17.2 \%$ \\
\hline Panamá & 397,786 & 19,855 & $5.0 \%$ & 379 & $0.1 \%$ & $1.9 \%$ \\
\hline Peru & $6,220,081$ & 405,387 & $6.5 \%$ & 6,390 & $0.1 \%$ & $1.6 \%$ \\
\hline Preferencial & $47,661,306$ & $16,351,371$ & $34.3 \%$ & 379,653 & $0.8 \%$ & $2.3 \%$ \\
\hline Bahamas & 296,207 & 35,318 & $11.9 \%$ & 4,623 & $1.6 \%$ & $13.1 \%$ \\
\hline Barbados & 48,951 & 4,529 & $9.3 \%$ & 123 & $0.3 \%$ & $2.7 \%$ \\
\hline Belize & 59,013 & 2,837 & $4.8 \%$ & 68 & $0.1 \%$ & $2.4 \%$ \\
\hline Bolivia & 974,538 & 67,513 & $6.9 \%$ & 919 & $0.1 \%$ & $1.4 \%$ \\
\hline Brasil & $25,875,697$ & $6,345,359$ & $24.5 \%$ & 249,995 & $1.0 \%$ & $3.9 \%$ \\
\hline Equador & $5,933,480$ & $3,524,431$ & $59.4 \%$ & 35,033 & $0.6 \%$ & $1.0 \%$ \\
\hline Guiana & 434,064 & 1,574 & $0.4 \%$ & 76 & $<0.1 \%$ & $4.8 \%$ \\
\hline Haiti & 895,200 & 247,676 & $27.7 \%$ & 56,005 & $6.3 \%$ & $22.6 \%$ \\
\hline Jamaica & 300,423 & 6,031 & $2.0 \%$ & 204 & $0.1 \%$ & $3.4 \%$ \\
\hline Paraguai & 150,231 & 11,290 & $7.5 \%$ & 638 & $0.4 \%$ & $5.7 \%$ \\
\hline Suriname & 60,716 & 4,590 & $7.6 \%$ & 59 & $0.1 \%$ & $1.3 \%$ \\
\hline Trinidade \& Tob. & $2,895,608$ & 390,373 & $13.5 \%$ & 3,651 & $0.1 \%$ & $0.9 \%$ \\
\hline Uruguai* & 535,074 & 233,146 & $43.6 \%$ & 11,605 & $2.2 \%$ & $5.0 \%$ \\
\hline Venezuela* & $9,202,106$ & $5,476,703$ & $59.5 \%$ & 16,654 & $0.2 \%$ & $0.3 \%$ \\
\hline Não-Preferencial & $4,645,811$ & $2,869,674$ & $61.8 \%$ & 115,829 & $2.5 \%$ & $4.0 \%$ \\
\hline Argentina & $4,645,811$ & $2,869,674$ & $61.8 \%$ & 115,829 & $2.5 \%$ & $4.0 \%$ \\
\hline Total & $397,621,104$ & $37,411,090$ & $9.4 \%$ & $1,053,659$ & $0.3 \%$ & $2.8 \%$ \\
\hline
\end{tabular}

Fonte: calculado da Comissão de Comércio Internacional dos EUA. Disponível em: $<$ https://dataweb.usitc.gov.com>.

* Observe que o Uruguai e a Venezuela receberam o tratamento SGP em 2016, mas perderam esse status a partir de $1^{\circ}$ de janeiro de 2017. 
Figura 1 - Participação do investimento estrangeiro direto dos EUA na América Latina, 1985-2015

(porcentagens total dos EUA)

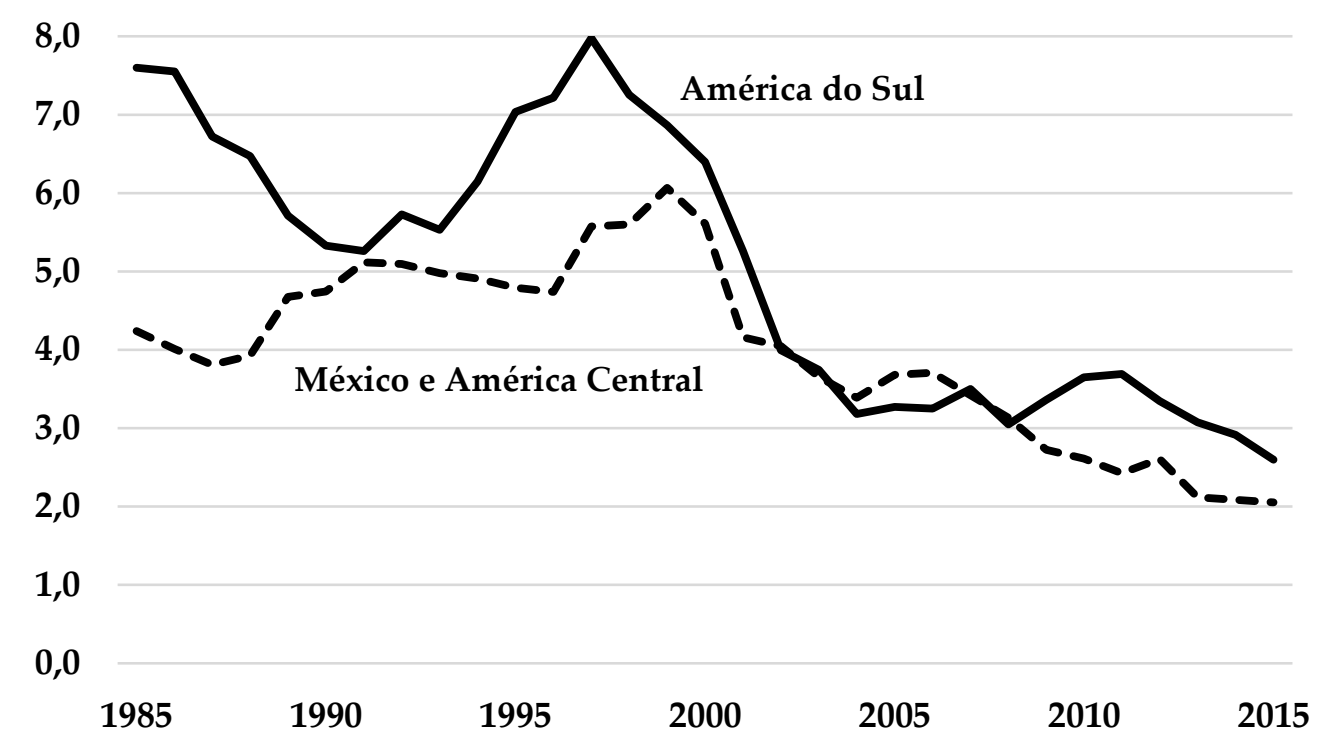

Fonte: Dados da Superintendência de Análise Econômica dos EUA. Disponível em $<$ https://www.bea.gov/itable/index.cfm>.

\section{Tendências no investimento}

O declínio do comércio interamericano foi complementado por uma relativa queda no investimento estrangeiro direto dos EUA na região. A Figura 1 mostra que a participação da região, no capital internacional dos EUA, realmente começou a diminuir na mesma época em que os EUA começaram a negociar acordos de livre acesso com parceiros selecionados da América Latina. A partir de 1995, quando o NAFTA entrou em vigor, $4,8 \%$ dos investimentos nos EUA foram para o México e a América Central; até 2015, a participação nesses países caiu para 2,1\%. A participação sul-americana atingiu um pico de 8,0\%, em 1997, vários anos antes das negociações dos EUA sobre os acordos de livre comércio chegarem à América Latina, mas, em 2015, eles hospedaram apenas 2,6\% do investimento estrangeiro direto dos EUA. 
A Tabela 2 oferece dados mais detalhados sobre a direção do capital de investimento dos EUA na região, estabelecendo distinções entre países conforme seus acordos comerciais e de investimento com os EUA. Ao contrário dos dados ilustrados na Figura 1, que dizem respeito à participação relativa da região nesse capital, os investimentos são medidos em termos absolutos. Não importa o relacionamento com os EUA, praticamente todos os países latino-americanos viram a taxa de investimento estrangeiro direto dos EUA aumentar mais lentamente em 2000-2015 do que em 1985-2000. Tomada como um todo, a taxa de aumento dos investimentos dos EUA, na região, foi quase dez vezes maior, em 1985-2000, do que seria em 2000-2015. Embora as experiências de países específicos variassem, uma regra é quase universal: com exceção de Honduras, todos os países da região viram o investimento dos EUA subir mais rápido no período anterior do que nos últimos anos. Vários países viram o declínio do investimento total dos EUA durante o período 2000-2015. Olhando especificamente para esse período mais recente, aqui não havia um padrão claro entre os destinatários. Em alguns casos, os investimentos subiram fortemente para os países com os quais os EUA possuem um Tratado Bilateral de Investimento - BIT (Bilateral Investment Treaties) (por exemplo, Uruguai), um FTA (por exemplo, El Salvador) ou ambos (por exemplo, Honduras). Pode-se também citar casos contrários em que os investimentos realmente diminuíram, apesar de o país em questão ter um BIT (por exemplo, Equador), um FTA (por exemplo, Costa Rica) ou ambos (por exemplo, Panamá). Tomados como um todo, os dados sustentam o ponto em que os fluxos de capital não são determinados unicamente, ou mesmo principalmente, pela relação legal entre as partes. 
Tabela 2 - Investimento direto estrangeiro dos EUA na América Latina e no Caribe, 1985-2015 (milhões de dólares Americanos)

\begin{tabular}{|c|c|c|c|c|c|c|}
\hline & & & Mudança & & & Mudança \\
\hline & 1985 & 2000 & $1985-2000$ & 2010 & 2015 & 2000-2015 \\
\hline Parceiros FTA \& BIT & 4,238 & 31,157 & $635.2 \%$ & 6,092 & 5,230 & $-83.2 \%$ \\
\hline Honduras & 169 & 399 & $136.1 \%$ & 936 & 1,175 & $194.5 \%$ \\
\hline Panamá & 4,069 & 30,758 & $655.9 \%$ & 5,156 & 4,055 & $-86.8 \%$ \\
\hline Parceiros FTA (s/ BIT) & 9,893 & 60,601 & $512.6 \%$ & 137,162 & 139,925 & $130.9 \%$ \\
\hline Chile & 255 & 10,052 & $3,842.0 \%$ & 30,747 & 27,331 & $171.9 \%$ \\
\hline Colômbia & 2,188 & 3,693 & $68.8 \%$ & 6,181 & 6,157 & $66.7 \%$ \\
\hline Costa Rica & 123 & 1,716 & $1,295.1 \%$ & 1,827 & 1,521 & $-11.4 \%$ \\
\hline Republica Dominicana & 227 & 1,143 & $403.5 \%$ & 1,432 & 1,357 & $18.7 \%$ \\
\hline El Salvador & 77 & 540 & $601.3 \%$ & 2,599 & 2,605 & $382.4 \%$ \\
\hline Guatemala & 211 & 835 & $295.7 \%$ & 1,110 & 1,100 & $31.7 \%$ \\
\hline México & 5,417 & 39,352 & $626.5 \%$ & 85,751 & 92,812 & $135.9 \%$ \\
\hline Nicarágua & 27 & 140 & $418.5 \%$ & 319 & 183 & $30.7 \%$ \\
\hline Peru & 1,368 & 3,130 & $128.8 \%$ & 7,196 & 6,859 & $119.1 \%$ \\
\hline Parceiros BIT (s/ FTA) & 3,143 & 19,109 & $508.0 \%$ & 14,259 & 15,324 & $-19.8 \%$ \\
\hline Argentina & 2,698 & 17,488 & $548.2 \%$ & 11,747 & 13,323 & $-23.8 \%$ \\
\hline Equador & 352 & 832 & $136.4 \%$ & 1,283 & 429 & $-48.4 \%$ \\
\hline Uruguai & 93 & 789 & $748.4 \%$ & 1,229 & 1,572 & $99.2 \%$ \\
\hline Outros Parceiros & 10,911 & 48,070 & $340.6 \%$ & 77,887 & 74,963 & $55.9 \%$ \\
\hline Bolivia & 201 & 403 & $100.5 \%$ & 535 & 489 & $21.3 \%$ \\
\hline Brasil & 9,110 & 36,717 & $303.0 \%$ & 66,963 & 65,272 & $77.8 \%$ \\
\hline Paraguai & 38 & 419 & $1,002.6 \%$ & 134 & 134 & $-68.0 \%$ \\
\hline Venezuela & 1,562 & 10,531 & $574.2 \%$ & 10,255 & 9,068 & $-13.9 \%$ \\
\hline Total & 28,185 & 158,937 & $463.9 \%$ & 235,400 & 235,442 & $48.1 \%$ \\
\hline
\end{tabular}

Nota: Os países não apresentados incluem alguns para os quais os dados não são fornecidos ou estão incompletos.

Nota: O total da América Latina e do Caribe inclui alguns países e territórios para os quais os dados são suprimidos na fonte por razões de confidencialidade comercial e/ou não são países membros do SELA.

Fonte: Dados da Superintendência de Análise Econômica dos EUA. Disponível em <https://www.bea.gov/itable/index.cfm>. 


\section{POLÍTICA ECONÔMICA ESTRANGEIRA NORTE-AMERICANA SOB O NOVO GOVERNO DOS EUA}

\section{Backlash anti-globalização}

Ao longo dos últimos governos, as relações comerciais entre os EUA e a região evoluíram de uma simples distinção de dois níveis para uma matriz mais variada. Durante muitos anos, a única grande diferença ocorreu entre um país da região sujeito a embargo (Cuba) e a todos os outros que receberam tratamento preferencial no âmbito do Sistema de Preferências Generalizadas - GPS (Generalized System of Preferences) e outros programas. Tudo isso mudou, como pode ser visto a partir dos dados de importação dos EUA na Figura 2. Além da negociação de acordos de livre comércio entre os EUA e onze países da região, nos últimos anos, também houve uma diminuição do tratamento preferencial para alguns países e o abrandamento das sanções contra Cuba. Entre os países que têm relações de FTA com os EUA, podemos fazer uma distinção adicional. Os quatro que compõem a Aliança do Pacífico são especialmente ativos, participando não só de vários acordos extraregionais, mas também nas negociações do Acordo de Comércio em Serviços - TiSA (Trade in Services Agreement). Três desses quatro países também participaram das mal sucedidas negociações da Cooperação Econômica Ásia-Pacífico - APEC (Asia-Pacific Economic Cooperation) e da Parceria Transpacífico - TPP (Trans-Pacific Partnership).

Futuros historiadores podem concluir que a eleição de Donald Trump e a reação mais ampla contra a globalização nos países industrializados constituem um choque tão grande para o sistema econômico mundial quanto o colapso do comunismo há uma geração atrás. Esses últimos desenvolvimentos podem desfazer muito do que foi realizado nos primeiros dias do início da década de 1990, quando o sistema comercial global foi transformado pela confluência de forças históricas gêmeas: o fim da Guerra Fria produziu um peace dividend ${ }^{1}$ para os países industrializados, e foi complementada pela aceitação generalizada entre os países em desenvolvimento da filosofia pró-mercado, pró-comércio, que se chamava então Consenso de Washington. Esse ambiente otimista ajudou a criar a Organização Mundial do Comércio (OMC) e a lançar numerosas negociações para os acordos de livre comércio entre países desenvolvidos e em desenvolvimento. O mais influente foi o Acordo de

${ }^{1}$ Dinheiro público que fica disponível para outros fins quando os gastos em defesa estão reduzidos. 
Livre Comércio da América do Norte - NAFTA (North American FTA) entre os EUA, México e Canadá, que entrou em vigor em 1994. O NAFTA criou um modelo OMC-Plus que desde então inspirou uma série de acordos nas Américas e em outros lugares. Em meados da década de 1990, também surgiu o advento das negociações comerciais megarregionais, incluindo a Área de Livre Comércio das Américas FTAA (Free Trade Area of the Americas) e um acordo planejado no fórum da Cooperação Econômica Ásia-Pacífico. Essas iniciativas bilaterais e regionais foram complementadas pelo lançamento das negociações da Rodada de Doha na OMC em 2001.

A maioria dessas negociações resultou em dificuldades severas. As megarregionais da FTAA e da APEC entraram em colapso nos primeiros anos do século XXI, mas vários dos participantes mais ambiciosos dessas negociações voltaram a uma série de negociações bilaterais que, em última instância, se juntaram, através de um processo bastante tortuoso na TPP. A Rodada de Doha perdeu a força em 2003, quando ficou claro que os EUA e a União Europeia já não tinham autoridade para determinar os resultados multilaterais. Apesar de inúmeros esforços para reviver essa iniciativa, mais notavelmente em 2008, ela agora parece morta. O Consenso de Washington deu lugar a uma bifurcação entre os países em desenvolvimento, como exemplificado pelas diferentes perspectivas da Aliança do Pacífico pró-comércio e da Aliança Bolivariana mais cética ao comércio. 
Figura 2 - Tratamento tributário das importações para os EUA da América Latina e do Caribe, 1996-2016 (bilhões de dólares atuais)

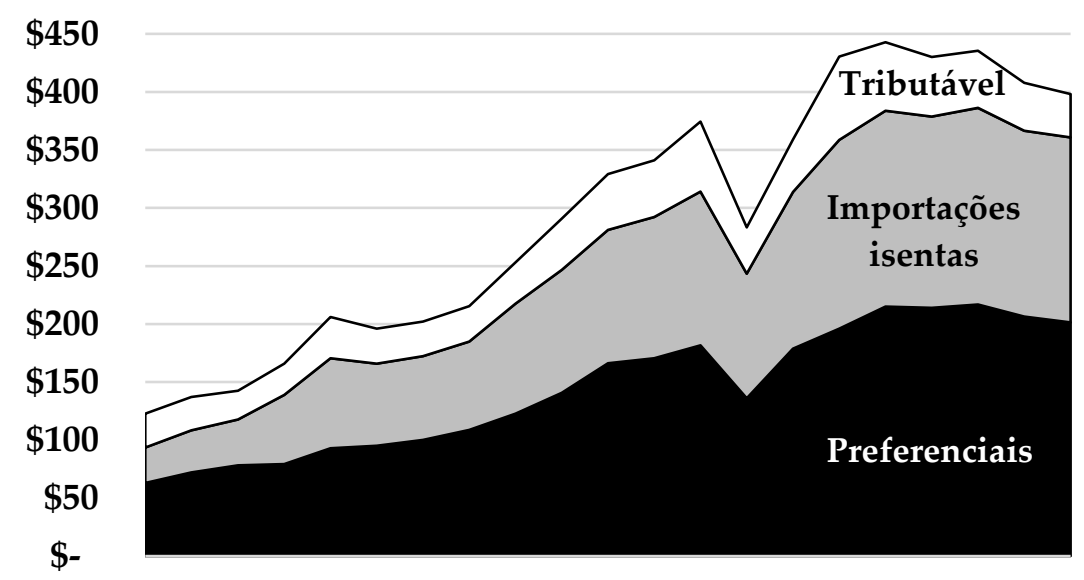

19961998200020022004200620082010201220142016

Fonte: calculado da Comissão de Comércio Internacional dos EUA. Disponível em: $<$ https://dataweb.usitc.gov>.

O desvio da globalização já estava em andamento antes de 2016, mas, naquele ano, acelerou rapidamente. $\mathrm{O}$ Reino Unido foi o epicentro da liberalização do comércio no século XIX e continuou sendo o principal defensor da globalização para as gerações a partir de então, mas, em 23 de junho, o eleitorado britânico escolheu por uma margem estreita (51,9$48,1 \%$ ) para forçar a sua saída da União Europeia (Brexit). Enquanto os EUA haviam retomado o antigo cargo do Reino Unido como primus inter pares no sistema comercial, esse papel foi posto em dúvida pela eleição de 8 de novembro - embora por uma margem ainda menor (46,1\% do voto popular) do que o Brexit - do primeiro presidente verdadeiramente protecionista dos EUA desde que Herbert Hoover deixou o cargo em 1933. Em seu discurso inaugural de 20 de janeiro de 2017, o presidente Donald Trump observou que estava derrubando décadas de política dos EUA. Toda decisão sobre o comércio, sobre impostos, sobre imigração, sobre assuntos estrangeiros, ele insistiu, seguirá, dali em diante, um princípios American First. Evitando deliberadamente a retórica pró-comércio favorecida por cada antecessor desde Franklin D. Roosevelt, o novo presidente insistiu que o protecionismo levaria a uma grande prosperidade e força. 
Donald Trump pode dever a sua eleição mais ao comércio do que a qualquer outra questão. Ele conseguiu ganhar a nomeação e as eleições gerais, executando uma plataforma protecionista que desafiou não só a ortodoxia econômica do Partido Republicano, mas também a sabedoria convencional da política dos EUA, prometendo retirar-se da TPP, renegociar o NAFTA e restringir as importações. Sua estratégia de campanha baseou-se na premissa aparentemente iludida de que ele poderia capturar os votos eleitorais de Estados industrializados que votaram consistentemente para candidatos presidenciais democratas desde a década de 1980. Isso foi precisamente o que aconteceu, confundindo as expectativas quase universais ao mover o Rust Belt dos Democratas para os Republicanos. As posições protecionistas do candidato são amplamente creditadas para alcançar esse resultado imprevisto.

O novo governo já deu um passo importante quando, no dia 23 de janeiro, o presidente retirou os EUA da TPP, um acordo pendente entre doze países, cujos membros incluíam Chile, México e Peru. A renegociação do NAFTA é outra prioridade. A presidência também sugeriu que, de tempos em tempos, pode recorrer a novos acordos bilaterais, mas ainda não sugeriu parceiros específicos para essas negociações. Também deixou a impressão de que levaria uma abordagem muito diferente à negociação e implementação de novos acordos comerciais, mas ainda não especificou quais os termos que poderia buscar de seus parceiros.

\section{O ressurgimento do protecionismo}

A discussão acima diz respeito ao que pode ser considerado como protecionismo passivo, através do qual o novo governo rejeita os acordos comerciais pendentes, ou o protecionismo semipassivo, pelo qual exige mudanças nesses acordos que estão em vigor. Essas iniciativas significam desfazer algumas das liberalizações que seus precursores alcançaram ao longo do último quarto de século. Há também a ameaça de prosseguir uma agenda mais ativa que resulte na imposição de novas barreiras ao comércio. Seja ativo ou passivo, o protecionismo do novo governo cumpre as promessas de campanha feitas aos trabalhadores dos EUA que há muito se consideraram estarem perdendo a globalização.

A maior manifestação do protecionismo do novo governo pode assumir a forma de leis de remédio comercial. Além das leis antidumping e de direitos compensatórios, que são mais comumente desencadeadas por

pleitos de empresas, esses estatutos incluem outros dois que foram pouco 
utilizados recentemente e envolvem um maior exercício de discrição das autoridades: o estatuto de segurança nacional e as salvaguardas.

O maior problema diz respeito ao aço. Em um memorando presidencial de 20 de abril de 2017 para o secretário de comércio, o presidente Trump dirigiu o início de um caso no âmbito da disposição de segurança nacional da lei comercial dos EUA. ${ }^{2}$ O Artigo 232 (b)(1)(A) da Lei de Expansão do Comércio de 1962 (Trade Expansion Act of 1962) fornece ampla autoridade para a imposição de restrições às importações que são consideradas prejudiciais à segurança nacional, tipicamente onde essas importações supostamente suprimem a produção doméstica e/ou para liderar a dependência de fontes estrangeiras para itens que são considerados vitais para a segurança nacional. $\mathrm{O}$ estatuto e os seus precursores datam da década de 1950 e tem sido frequentemente associado a segurança energética. Foi raramente invocado, tendo atingido seu pico nas décadas de 1970 e 1980 . O secretário tem até 270 dias para conduzir a investigação. Se o secretário do comércio considerar que o aço está sendo importado para os EUA em tais quantidades ou circunstâncias que ameaçam prejudicar a segurança nacional, ele pode recomendar medidas específicas que devem ser tomadas para ajustar as importações. A imposição real dessas medidas seria uma decisão presidencial. $\mathrm{O}$ memorando orientou o secretário de comércio a basear sua decisão em fatores como a produção doméstica de aço necessária para os requisitos de defesa nacional projetados e a capacidade das indústrias nacionais para atender a tais requisitos; as disponibilidades existentes e antecipadas dos recursos humanos, produtos, matérias-primas e outros suprimentos e serviços essenciais para a defesa nacional. Entre os outros fatores que o presidente ordenou ao secretário a levar em conta, estão o status e a provável eficácia dos esforços dos EUA para negociar uma redução nos níveis de excesso de capacidade de aço em todo o mundo. Esse último ponto sugere que o propósito em pedir essa investigação pode ser criar alavancagem sobre outros países em um novo esforço para negociar um acordo global para a gestão do comércio do aço.

Exatamente uma semana depois de iniciar essa controvérsia acerca do aço, o presidente Trump seguiu com a mesma orientação em relação ao alumínio. ${ }^{3}$ Do ponto de vista da região, a única diferença é em que os países podem ser afetados por quaisquer restrições de importação resultantes. Alguns países fornecem alumínio e aço aos EUA (ou seja, Argentina, Brasil, Colômbia, México e Venezuela), enquanto outros

${ }^{2}$ Disponível em: $<$ https://www.whitehouse.gov/the-pressoffice/2017/04/20/presidential-memorandum-secretary-commerce $>$.

${ }^{3}$ Disponível em: <https://www.whitehouse.gov/the-pressoffice/2017/04/27/presidential-memorandum-secretary-commerce $>$. 
exportam aço, mas não o alumínio (ou seja, Chile, República Dominicana, Guatemala e Trinidad e Tobago).

Outra maneira pela qual o novo governo poderia exercer o protecionismo é por meio do deferimento de pedidos formulados sob a lei de salvaguarda. Ao contrário das leis de direitos antidumping e compensatórios, que são implementadas por agentes políticos de nível inferior, de acordo com critérios objetivos, as salvaguardas dependem, em última instância, de uma decisão política ao nível presidencial. O uso desta lei tem sido claramente circunscrito no tempo desde a conclusão das negociações comerciais da Rodada do Uruguai, em 1994, que produziu um novo Acordo de Salvaguardas que - como interpretado por painéis da OMC - tornou impossível para os países imporem restrições capazes de sobreviver a um litígio no Orgão de Solução de Controvérsias - DSB (Dispute Settlement Body) da OMC. A última vez que um presidente dos EUA invocou esta lei foi em 2001, quando o presidente George W. Bush estendeu proteção para a indústria siderúrgica. No entanto, podemos notar um ressurgimento no uso dessa lei, como evidenciado em 26 de abril de 2017, quando uma empresa (Suniva, Inc.) apresentou uma petição à Comissão de Comércio Internacional dos EUA - USITC (United States International Trade Commission), buscando proteção contra importações de células e módulos fotovoltáicos de silício cristalino. A USITC agora tem seis meses para determinar se o aumento das importações desses produtos é uma causa substancial de ferimentos graves para a indústria. Se fizer uma determinação afirmativa, a comissão pode recomendar ao presidente que ele imponha tributos, cotas ou outras restrições sobre essas importações. O presidente terá então ampla margem de discricionariedade para aceitar, rejeitar ou modificar essas recomendações. Esse caso pode testar se a nova administração, que expressou dúvidas sobre se as regras e os acordos da OMC são favoráveis aos interesses dos EUA, está preparada para tomar uma ação que seja praticamente uma violação das regras dessa organização.

\section{O retorno das ameaças retaliatórias}

A abordagem do novo governo para a política de comércio significou um retorno aos estilos de negociação que não têm sido proeminentes desde o início dos anos 90. Antes da criação da OMC, em 1995, os EUA muitas vezes procuravam pressionar seus parceiros por meio de leis de reciprocidade. Esses estatutos, principalmente a seção 301 da Lei de Comércio de 1974 (com sua redação alterada), permitiram que o executivo impusesse sanções aos países que violassem as prerrogativas 
comerciais dos EUA. Essa tática foi especialmente popular durante a presidência de Ronald Reagan (1981-1988). Embora essa abordagem agressiva das negociações tenha levado a uma grande fricção no sistema comercial, também é creditada, em alguns círculos, por levar a uma grande negociação: que os EUA se abstenham de tais ameaças em troca da criação de uma nova ordem comercial em que a OMC abrangeu uma gama muito maior de questões e em que o sistema de solução de controvérsias é forte. Desde então, a seção 301 e os estatutos relacionados recuaram para a memória histórica. Há sinais de que o novo governo dos EUA irá reverter a direção e, mais uma vez, depender da pressão unilateral para coagir seus parceiros.

Os EUA gozam de vantagens importantes na alavancagem do comércio. Possuem o maior mercado do mundo e, no entanto, sua economia é uma das menos intensivas em comércio. As exportações de bens e serviços representaram apenas $12,6 \%$ do PIB dos EUA, em 2015, ou menos da metade da média mundial de $29,5 \%$. Embora tenha também um portfólio altamente diversificado de parceiros comerciais, os EUA são o maior ou o segundo maior mercado para muitos deles. Como esse país pesa mais fortemente com seus parceiros comerciais (individual e coletivamente) do que vice-versa, restringir o comércio será mais prejudicial ao parceiro do que aos EUA. Portanto, não é de admirar que gerações sucessivas de estadistas dos EUA tenham visto vantagens em alavancar sua posição econômica. Às vezes, eles fizeram isso com os objetivos comerciais em mente (reciprocidade) e às vezes para fins políticos (sanções). De qualquer forma, a ameaça é a mesma: se um parceiro não satisfizer às demandas dos EUA por mudanças em algum aspecto de suas políticas, os EUA podem fazer retaliações. Essa retaliação normalmente assumirá a forma de alíquotas mais elevadas ou proibições definitivas sobre o acesso dos países ao mercado americano.

O grau de vulnerabilidade a essas ameaças varia consideravelmente de um país para outro. Devemos esperar que a alavancagem dos EUA seja maior em qualquer relacionamento para o qual duas condições sejam atendidas: (1) o comércio bilateral é equivalente a uma grande parcela da economia do parceiro, e (2) esse mesmo fluxo representa uma pequena parcela da economia dos EUA. Deixando de lado a questão limiar de onde desenhamos a linha entre grande e pequeno, é evidente que países que são geograficamente próximos dos EUA são especialmente vulneráveis à pressão. Para dar um exemplo extremo, considere o comércio total de US\$ 4,6 bilhões entre os EUA e a Nicarágua em 2016. Isso foi igual a 36\% do PIB na Nicarágua, mas apenas $0,04 \%$ do PIB dos EUA. À medida que se move mais para o sul, a alavancagem potencial dos EUA diminui especialmente quando se trata de economias maiores. A Argentina teve 
US\$ 11,8 bilhões em comércio com os EUA, em 2016, por exemplo, que era igual a $2 \%$ da economia argentina. Esse número ainda é sensivelmente grande, mas, em uma ordem de grandeza, diferente de $36 \%$ da Nicarágua.

\section{O impacto da rivalidade sino-americana em terceiros}

Tomando uma visão maior, as tendências analisadas aqui refletem o ritmo acelerado de mudança na economia política global. O Brexit e os resultados eleitorais dos EUA são apenas os maiores exemplos de como os eleitorados em alguns países industrializados estão respondendo a tendências de longo prazo nas economias globais e nacionais, que alguns percebem como um mecanismo pelo qual a riqueza é redistribuída entre e dentro dos países. As partes nacionais da economia global pouco mudaram durante as décadas de encerramento do século XX. A parcela do PIB mundial controlada pelos EUA e os outros países industrializados do Grupo dos Sete (G-7) passou de 67,4\%, em 1970, para 65,8\%, em 1985, e, em seguida, para $65,6 \%$ em 2000 . O ritmo de mudança acelerou bastante desde a virada do século, como pode ser visto na Tabela 3. A participação do G-7 na riqueza global caiu de quase dois terços para menos da metade, enquanto a do BRICS (Brasil, Rússia, Índia, China e África do Sul) quase triplicou. $\mathrm{O}$ tamanho relativo dos EUA em relação à região também mudou. A partir de 1985, a economia dos EUA era 5,8 vezes maior que o tamanho combinado de todos os países da América Latina e do Caribe. Até 2015, essa diferença caiu para 3,4 vezes. 
Tabela 3 - Participação na Economia Global, 1985-2015

(participação de países e regiões do PIB global)

\begin{tabular}{|c|c|c|c|c|c|}
\hline & & & Mudança & & Mudança \\
\hline & 1985 & 2000 & $1985-2000$ & 2015 & $2000-2015$ \\
\hline G-7 & 65.8 & 65.6 & -0.2 & 46.4 & -19.2 \\
\hline United States & 34.4 & 30.7 & -3.7 & 24.3 & -6.4 \\
\hline Outros G-7 & 31.4 & 34.9 & +3.5 & 22.1 & -12.8 \\
\hline BRICS menos Russia* & 6.6 & 7.4 & +1.6 & 20.5 & +13.1 \\
\hline China & 2.4 & 3.6 & +1.2 & 14.9 & +11.3 \\
\hline Brasil & 1.7 & 2.0 & +0.3 & 2.4 & +0.4 \\
\hline India e África do Sul & 2.4 & 1.8 & -0.6 & 3.2 & +1.4 \\
\hline Outros Latinos e Caribenhos & 4.2 & 4.8 & +0.6 & 4.7 & +0.1 \\
\hline México & 1.5 & 2.0 & +0.5 & 1.5 & -0.5 \\
\hline Resto da Região & 2.7 & 2.8 & +0.1 & 3.2 & +0.4 \\
\hline Resto do Mundo & 23.4 & 22.2 & -0.8 & 28.4 & +6.2 \\
\hline Mundo & 100.0 & 100.0 & 100.0 & 100.0 & 100.0 \\
\hline
\end{tabular}

Fonte: calculado a partir de dados do Banco Mundial. Disponível em:

$<$ http://data.worldbank.org/indicator/NY.GDP.MKTP.CD>.

“Outros G-7" são a soma do Canadá, França, Alemanha, Itália, Japão e Reino Unido.

* Note-se que a Rússia está excluída desse cálculo porque os dados do Banco Mundial não estão disponíveis no PIB da União Soviética e, portanto, as comparações com 1985 não são possíveis. A Rússia manteve $0,8 \%$ do PIB global em 2000 e 1,8\% em 2015, o que significa que o BRICS como grupo cresceu de 8,2\% do PIB global em 2000 para 22,3\% em 2015 (um ganho de 14,1 pontos).

A economia chinesa cresceu ainda mais rápido do que a economia dos EUA nas últimas décadas. A posição global relativa dos EUA em relação à China alcançou um pico, em 1987, quando a economia dos EUA foi 17,8 vezes maior do que a da China, mas, em 2015, essa proporção caiu para 1,6 vezes. É amplamente esperado que a China ultrapasse os EUA, em números absolutos, em uma ou duas décadas e que o tom de mudança dessa relação bilateral terá um impacto significativo no sistema de comércio global. No caso de esses dois gigantes se deslizarem para uma guerra comercial, isso poderia causar danos colaterais a terceiros.

O estado das relações entre os EUA e a China, no novo governo, é um trabalho em andamento e a política atual pode desviar-se drasticamente da retórica da campanha. Quando Donald Trump concorreu à 
presidência, ele frequentemente atacou a China, declarando-a como um manipulador de moeda e que, por isso, ele iniciaria um processo que poderia resultar na imposição de sanções à China. Uma vez no cargo, no entanto, ele realizou um encontro produtivo com seu homólogo chinês e adotou uma linha muito mais suave, em parte, devido à necessidade de colaboração sino-americana em lidar com a Coréia do Norte. A declaração da China como um manipulador de moeda não está mais na mesa, embora existam outras alavancas que possam ser puxadas na competição dos EUA com a segunda maior economia do mundo. 
Tabela 4 - Importância relativa dos comércios norte-americano e chinês para os países da América Latina e do Caribe, 2015

(porcentagem de participação nas importações e exportações totais do país)

\begin{tabular}{|c|c|c|c|c|c|c|}
\hline & \multicolumn{3}{|c|}{ Origem das Importações } & \multicolumn{3}{|c|}{ Destinatinação das Exportações } \\
\hline & EUA & China & Diferença & EUA & China & Diferença \\
\hline \multicolumn{7}{|c|}{ Países nos quais os EUA são tanto o maior fornecedor, quanto o maior consumidor } \\
\hline Haiti & $20.3 \%$ & $18.2 \%$ & $2.1 \%$ & $82.7 \%$ & $0.9 \%$ & $81.8 \%$ \\
\hline México & $47.3 \%$ & $17.7 \%$ & $29.6 \%$ & $81.2 \%$ & $1.7 \%$ & $79.5 \%$ \\
\hline Nicarágua & $18.0 \%$ & $14.4 \%$ & $3.6 \%$ & $54.1 \%$ & $0.5 \%$ & $53.6 \%$ \\
\hline Bahamas & $81.8 \%$ & $0.1 \%$ & $81.7 \%$ & $52.7 \%$ & $<0.1 \%$ & $52.7 \%$ \\
\hline República Domicana & $41.0 \%$ & $13.3 \%$ & $27.7 \%$ & $50.3 \%$ & $1.4 \%$ & $48.9 \%$ \\
\hline El Salvador & $39.4 \%$ & $8.1 \%$ & $31.3 \%$ & $47.0 \%$ & $0.8 \%$ & $46.2 \%$ \\
\hline Trinidad e Tobago & $25.1 \%$ & $6.5 \%$ & $18.6 \%$ & $42.8 \%$ & $0.2 \%$ & $42.6 \%$ \\
\hline Costa Rica & $39.5 \%$ & $12.5 \%$ & $27.0 \%$ & $40.8 \%$ & $0.8 \%$ & $40.0 \%$ \\
\hline Belize & $33.4 \%$ & $10.0 \%$ & $23.4 \%$ & $38.9 \%$ & $1.0 \%$ & $37.9 \%$ \\
\hline Equador & $27.1 \%$ & $15.3 \%$ & $11.8 \%$ & $39.5 \%$ & $3.9 \%$ & $35.6 \%$ \\
\hline Honduras & $35.2 \%$ & $13.6 \%$ & $21.6 \%$ & $36.0 \%$ & $0.5 \%$ & $35.5 \%$ \\
\hline Jamaica & $37.4 \%$ & $8.2 \%$ & $29.2 \%$ & $36.3 \%$ & $2.2 \%$ & $34.1 \%$ \\
\hline Guatemala & $37.1 \%$ & $10.6 \%$ & $26.5 \%$ & $35.0 \%$ & $1.9 \%$ & $33.1 \%$ \\
\hline Guiana & $19.6 \%$ & $5.2 \%$ & $14.4 \%$ & $24.2 \%$ & $1.6 \%$ & $22.6 \%$ \\
\hline Venezuela & $18.4 \%$ & $15.3 \%$ & $3.1 \%$ & $35.4 \%$ & $12.9 \%$ & $22.5 \%$ \\
\hline Colombia & $32.5 \%$ & $17.3 \%$ & $15.2 \%$ & $27.5 \%$ & $5.2 \%$ & $22.3 \%$ \\
\hline Panamá & $25.9 \%$ & $9.5 \%$ & $16.4 \%$ & $19.7 \%$ & $5.9 \%$ & $13.8 \%$ \\
\hline Suriname & $23.1 \%$ & $8.3 \%$ & $14.8 \%$ & $10.5 \%$ & $2.4 \%$ & $8.1 \%$ \\
\hline Barbados & $39.0 \%$ & $5.6 \%$ & $33.4 \%$ & $3.4 \%$ & $<0.1 \%$ & $3.4 \%$ \\
\hline \multicolumn{7}{|c|}{ Países para os quais a China é o maior fornecedor, e os EUA são o maior consumidor } \\
\hline Bolivia & $10.6 \%$ & $17.9 \%$ & $-7.3 \%$ & $12.1 \%$ & $5.3 \%$ & $6.8 \%$ \\
\hline Paraguai & $7.8 \%$ & $23.5 \%$ & $-15.7 \%$ & $1.8 \%$ & $0.4 \%$ & $1.4 \%$ \\
\hline \multicolumn{7}{|c|}{ Países para os quais a China é tanto o maior fornecedor, quanto o maior consumidor } \\
\hline Cuba & $2.7 \%$ & $28.7 \%$ & $-26.0 \%$ & $0.0 \%$ & $0.9 \%$ & $-0.9 \%$ \\
\hline Argentina & $12.9 \%$ & $19.7 \%$ & $-6.8 \%$ & $6.0 \%$ & $9.1 \%$ & $-3.1 \%$ \\
\hline Brasil & $15.6 \%$ & $17.9 \%$ & $-2.3 \%$ & $12.7 \%$ & $18.6 \%$ & $-5.9 \%$ \\
\hline Peru & $20.7 \%$ & $22.7 \%$ & $-2.0 \%$ & $15.2 \%$ & $22.1 \%$ & $-6.9 \%$ \\
\hline Uruguai & $9.0 \%$ & $18.4 \%$ & $-9.4 \%$ & $6.7 \%$ & $13.7 \%$ & $-7.0 \%$ \\
\hline Chile & $18.8 \%$ & $23.4 \%$ & $-4.6 \%$ & $13.2 \%$ & $26.3 \%$ & $-13.1 \%$ \\
\hline \multicolumn{7}{|l|}{ Média Simples } \\
\hline para a Região & $27.4 \%$ & $14.1 \%$ & $13.3 \%$ & $30.6 \%$ & $5.6 \%$ & $25.0 \%$ \\
\hline
\end{tabular}

Fonte: calculado das estatísticas do Diretor de Comércio do FMI. Disponível em: $<$ http://data.imf.org/regular.aspx?key=61013712>. 
Para a maioria dos países da região, a China e os EUA representam coletivamente entre um terço e metade de todas as importações e, geralmente, enviam uma parcela comparativamente elevada de suas exportações para esses dois gigantes. Em média, os EUA são duas vezes mais importantes que a China para as importações do países da América Latina ou do Caribe e cinco vezes mais importantes para suas exportações. A importância relativa desses parceiros varia enormemente dentro do grupo. Existem mais países na região para os quais o comércio com os EUA permanece maior que o comércio com a China, como pode ser visto a partir dos dados na Tabela 4, mas isso provavelmente mudará ao longo do tempo. Os dados mostram um padrão geográfico muito simples pelo qual a importância relativa dos EUA é uma função da distância, de modo que o comércio dos EUA é mais importante para os países da Bacia do Caribe e seus arredores e a China aumenta importância quando se viaja mais para o sul. As únicas grandes exceções a essa regra geral são Cuba (onde os EUA pesam menos do que a geografia simples ditaria) e o Equador (onde o inverso é verdadeiro). A China é um parceiro especialmente grande para os países que estão dentro ou ao redor do Cone Sul. Ter um acordo de livre comércio com os EUA não altera esse padrão geral, como mostrado nos casos do Chile e do Peru.

Além do aumento do peso econômico da China no comércio com a região, há também a questão de saber se os países entrarão em relações preferenciais com esse parceiro. A China é um negociador cada vez mais ativo de acordos de livre comércio, mas só começou a concluí-los fora da Ásia e do Pacífico. A partir de 2016, a China tinha acordos de livre comércio com 20 países naquela região, incluindo Chile, Costa Rica e Peru, mas com apenas dois parceiros em outras partes do mundo. Também estava negociando ativamente vários outros acordos de livre comércio, bem como uma Parceria Econômica Abrangente Regional RCEP (Regional Comprehensive Economic Partnership), que muitos veem como uma resposta chinesa à TPP, agora moribunda. Nenhuma das negociações a que a China se dedica agora se envolve com países da América Latina e do Caribe, mas a Colômbia é um dos seis países sob consideração ativa como parceiro de negociação de livre comércio. Se todos esses acordos potenciais fossem concluídos, aprovados e implementados, a China teria trinta e sete parceiros de FTA - quase o dobro do que os atuais 20 parceiros de FTA dos EUA. Mesmo nesse cenário, no entanto, os EUA ainda teriam mais acordos com os países da América Latina e do Caribe (dez) do que a China (quatro).

\section{CONCLUSÕES}

O objetivo principal desta análise é fornecer fatos e análises, em vez 
de argumentos e propostas, mas isso não existe em um vácuo político. As relações econômicas com os EUA são de grande importância para todos os países da América Latina e do Caribe, embora em diferentes graus, e cabe a eles - individual e coletivamente - considerar como melhor responderão aos desenvolvimentos discutidos nas páginas anteriores. Esta seção conclusiva não apresenta sugestões específicas para políticas nacionais ou regionais, mas oferece algumas orientações sobre como essas políticas podem levar em consideração as novas realidades da política econômica estrangeira dos EUA.

\section{O que o desengajamento econômico dos EUA significa para a região}

O principal tema explorado ao longo desta análise tem sido o desengajamento econômico dos EUA na região, uma tendência que não pode ser atribuída exclusivamente às mudanças súbitas da nova administração em relação ao comércio, imigração e cooperação internacional. $\mathrm{O}$ novo presidente dos EUA difere fortemente de seus antecessores em relação à perspectiva, à retórica, ao estilo e à política, mas seria um erro assumir que a mudança de natureza das relações econômicas dos EUA com a região é uma função simples da liderança. Pelo contrário, os dados analisados aqui demonstram que esse desengajamento estava bem avançado muito antes de Donald Trump assumir o cargo. Apesar de as barreiras tributárias serem agora uma fração de seus níveis anteriores, e apesar da negociação de acordos de livre comércio com muitos países da região, os EUA, gradualmente, diminuíram em importância relativa enquanto parceiro comercial, investidor e doador externo de assistência. $\mathrm{O}$ novo governo pode acelerar essa tendência através de palavras e ações que violam o protocolo diplomático ou até mesmo violam obrigações legais. É razoável supor que, até 2020, a pegada econômica dos EUA na região será menor ainda do que em 2016, mas só se pode especular sobre a medida em que isso será o produto das prioridades e ações do novo governo.

Para entender o que essas tendências significam para a região, devemos reconhecer uma tensão em como esses interesses são definidos. Por um lado, os atores políticos e os líderes empresariais da América Latina e do Caribe desejaram consistentemente os benefícios decorrentes das relações econômicas com os EUA, incluindo não apenas o acesso ao maior mercado mundial, mas também (entre outras coisas) capital de investimento e assistência estrangeira. Por outro lado, os formuladores 
de políticas e a sociedade civil, na região, têm preocupações, consistentemente manifestadas, acerca do domínio econômico e político dos EUA. Muitas vezes, é difícil conciliar os desejos contraditórios implicados por esse duplo desiderato, e é possível que os desenvolvimentos discutidos aqui sejam apenas bem-vindos para alguns políticos e analistas à medida que são malvistos para outros.

Em vez de resolver as tensões inerentes entre esses dois objetivos, o que poderia facilmente se degenerar em um conflito, poderíamos focar tendências mais específicas, como a aparente disponibilidade do governo dos EUA para tomar ações que possam violar suas obrigações internacionais e sua forte preferência pela bilateralidade em relação à multilateralidade. Essas tendências colocam problemas específicos e sequenciais que atores políticos precisam considerar a nível nacional e para os quais as respostas regionais também podem ser justificadas.

\section{Os riscos para o sistema de negociação multilateral}

$\mathrm{O}$ mais imediato desses problemas diz respeito à possibilidade iminente de que os EUA possam tomar ações que violem suas obrigações internacionais. O novo governo já iniciou um caminho que poderia levar à ameaça - e talvez a realidade - de uma retirada dos EUA da OMC. E mesmo que Washington não tome um passo tão precipitado, a relevância do sistema de comércio multilateral poderia ser seriamente prejudicada pelo seu próprio fracasso contínuo em exercer sua função legislativa.

O novo governo pode impor restrições ao aço e ao alumínio, citando a segurança nacional como a justificativa de suas ações (ou seja, a necessidade de manter a produção doméstica dessas duas commodities para atender às demandas das indústrias de defesa). Os problemas legais colocados por esses dois casos são mais complexos do que o que poderia surgir, em princípio, na medida em que as questões relacionadas à segurança nacional formam um "ponto cego" na jurisprudência da OMC. Desde o advento do sistema comercial multilateral, em 1947, a exceção de segurança nacional do artigo XXI do Acordo Geral de Tarifas e Comércio - GATT (General Agreement on Tariffs and Trade) deu aos países ampla liberdade para praticar atos atentatórios ao GATT que considerem necessárias em função da segurança nacional. Ao contrário das exceções mais mundanas previstas no Artigo XX do GATT, que trata de ações que os países poderiam tomar por outros motivos (por exemplo, saúde humana), as invocações do Artigo XXI do GATT foram tradicionalmente aceitas sem desafio. A negociação implícita aqui sempre foi que o sistema comercial não exigirá que os países forneçam justificativas para suas 
políticas de defesa e os membros desse sistema não abusarão desse privilégio invocando a segurança nacional frivolamente.

Se o novo governo impõe restrições ao aço e/ou ao alumínio e afirma fazê-lo por motivos de segurança nacional, pode forçar seus parceiros incluindo os países da América Latina e do Caribe - a escolher entre três opções ruins. Eles podem desafiar essa ação no DSB, mas depois recuar quando os EUA invocarem o Artigo XXI do GATT. Isso poderia encorajar outros países a abusar desse vazio da mesma forma. Alternativamente, eles podem quebrar com todos os precedentes e exigir, em tal caso, que os EUA provem, em um painel de resolução de disputas, que a sua invocação de segurança nacional é justificada pelos fatos. Essa provocação pode dar aos novos governos motivos para decidir que a OMC ultrapassou seus limites e superou sua utilidade. Em outra alternativa, os parceiros dos EUA podem ignorar completamente o desafio legal e simplesmente impor restrições para as importações dos EUA (seja desses metais ou outros produtos relacionados à defesa). Argumentos podem ser feitos a favor ou contra as três dessas opções, mas todos compartilham a mesma desvantagem: cada um deles ajudaria a minar e talvez até a eliminar a OMC como uma instituição internacional viável.

Um problema semelhante pode ser apresentado por outras ações em consideração nos EUA, mas para o qual o nível de risco pode ser menor. As apostas provavelmente seriam muito mais baixas para um caso focado em uma questão comercial comum do que seria para assuntos relacionados à segurança nacional, mas, mesmo assim, não se poderia descartar os riscos. É possível que o novo governo simplesmente ignore as decisões de resolução de disputas de lhe desagradam; no caso de os seus parceiros da $\mathrm{OMC}$ retaliarem, o novo governo poderá responder em espécie. Os perigos podem, portanto, ser semelhantes aos que são colocados pelos casos de segurança nacional. Ironicamente, os interesses dos parceiros dos EUA podem ser melhor atendidos se os EUA apresentassem mais reclamações próprias ao DSB, demonstrando que os atores políticos norte-americanos ainda percebem um benefício na manutenção do sistema multilateral. A esse respeito, é um pouco desencorajador notar que o novo governo ainda não apresentou uma única reclamação durante o primeiro semestre. Isso não é tão incomum, com seus dois predecessores imediatos tendo trazido apenas uma reclamação durante os primeiros anos, mas, até que o novo governo use esse sistema de resolução de disputas, encorajará questionamentos.

Mesmo que o sistema consiga evadir dos perigos colocados por esses possíveis casos de resolução de disputas, ele ainda enfrenta um problema sério que antecede o advento de Donald Trump. Começando com o 
processo alongado pelo qual a Rodada de Doha foi lançada, em 19992001, através das tentativas fracassadas de resolver essas negociações em 2003, 2008 e além, ficou dolorosamente evidente que os membros desta organização foram incapazes de obter um sim em grandes acordos comerciais. Esse poderia muito bem ter permanecido o caso, se o eleitorado dos EUA tivesse escolhido um presidente mais ortodoxo, mas as perspectivas de revitalização da OMC como instituição normativa são nulas enquanto a política dos EUA seja explicitamente hostil ao multilateralismo. Por essas razões, praticamente não há valor na discussão sobre se ou como os países da América Latina e do Caribe tentariam revigorar esse sistema. Para o futuro previsível, seus interesses podem ser melhorados fazendo o que for necessário para manter esse sistema à tona, na esperança de que ele possa ser revivido mais tarde. No curto e médio prazo, suas energias podem ser melhor orientadas para opções em outros fóruns.

Análise das Relações Econômicas, Comerciais e de Cooperação da América Latina e do Caribe com os Estados Unidos da América Analysis of Economic, Trade and Cooperation Relations of Latin America and the Caribbean with the United States of America Submetido em: 2017-09-22 Aceito em: 2018-01-30 